\title{
Diagnostic Value of I/T2 Ratio in Neonatal Sepsis: A Prospective Comparative Study.
}

\author{
Swathi S Sanjee ${ }^{1}$, Aswathy Rajan², Ashvij R Shriyan ${ }^{3}$, Santosh T Soans ${ }^{4}$ \\ ${ }^{1}$ Post Graduate, Department of Pediatrics, A. J. Institute of Medical Sciences, Mangalore, ${ }^{2}$ Assistant Professor, Department of Pediatrics, A. J. Institute Of Medical \\ Sciences, Mangalore, ${ }^{3}$ Consultant Neonatologist, Department of Pediatrics, A. J. Hospital and Research Centre, Mangalore, ${ }^{4}$ Professor and Head, Department of Pediatrics, \\ A. J. Institute of Medical Sciences, Mangalore.
}

\section{Abstract}

Background: Neonatal sepsis accounts for early-half of all neonatal death in India. Although the gold standard for the diagnosis of neonatal sepsis is by blood culture, there is a need for a test that is cheap, accurate, easily performed with quick availability of reports so that prompt and appropriate treatment is ensured. In this study we try to analyse the diagnostic value of I/T2ratio in comparison to I/T ratio and absolute neutrophil count (ANC) independently to correctly predict neonatal sepsis. Subjects and Methods: A time bound, prospective comparative study was done on neonates with suspected neonatal sepsis for a 2 year period. Neonates were then analysed in three groups depending on their blood culture results as no sepsis, probable sepsis and proven sepsis. I/T2was calculated for all the babies and an optimum cut off was found for the same. The diagnostic accuracy of I/T2 ratio with septic screen positivity and blood cultures were assessed. Results: 245 neonates included in the study were divided into three groups depending on whether they were blood culture positive sepsis, probable or clinical sepsis. The means of septic screen parameters including I/T2 were highly significant when compared between the three groups (p value $<0.001$ ). ROC curve created showed the AUC for I/T, I/T2 and ANC was 0.822, 0.809, 0.610 (p value <0.001) and a higher specificity. Conclusion: I/T2 shows promise as a parameter to screen for sepsis in neonates. Calculating the I/T2 ratio in conjunction with established septic screen parameters could enhance prediction of sepsis in newborns.

Keywords: I/T2 ratio, neonatal sepsis, I/T ratio, ANC.

Corresponding Author: Dr. Aswathy Rajan, Assistant Professor, Department of Pediatrics, A. J. Institute Of Medical Sciences, Mangalore.

Received: January 2019

Accepted: January 2019

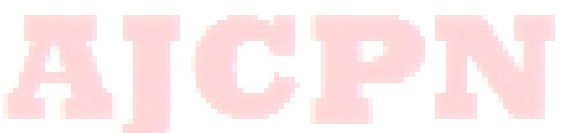

\section{Introduction}

Neonatal sepsis is frequent and important cause of morbidity and mortality particularly in the developing countries, like India and accounts for early-half of all neonatal death in our country. The incidence of neonatal sepsis in India is 30 per 1000 live births. ${ }^{[1]}$ Some population-based studies have reported clinical sepsis rates ranging from 49 to $170 / 1000$ live births in rural India. ${ }^{[2]}$ Incidence is not changed much over the past decade, and the fatality due to sepsis is between $30 \%$ and $65 \%$. ${ }^{[3]}$

Gold standard for the diagnosis of neonatal sepsis is by demonstration of the organisms in blood culture, but it takes a long time of 2-8 days for positive culture, the cost is relatively expensive and has low positive rate and hence various other investigations are necessary for early diagnosis or to rule out sepsis. ${ }^{[4]}$ Therefore, there is a need for a test that is cheap, accurate, easily performed with quick availability of reports so that prompt and appropriate treatment is ensured. Many studies have investigated the utility of ratio of immature neutrophils compared to total neutrophils (I/T ratio), the results of which might have to be read with caution in neonates in whom the total white blood cell (WBC) counts may be lowered. But not many studies have been done on the utility of immature to total neutrophil square ratio (IT2) which might be a better indicator of neonatal sepsis. In this study we try to analyse the diagnostic value of IT2 ratio in comparison to IT ratio and absolute neutrophil count (ANC) independently to correctly predict neonatal sepsis.

\section{Subjects and Methods}

\section{Study population}

A time bound, prospective comparative study was done on all neonates admitted to neonatal intensive care unit of $\mathrm{AJ}$ Institute of Medical Sciences, Mangalore, India from November 2016 to July 2018 with suspected neonatal sepsis. All neonates $>32$ weeks of gestation admitted to neonatal intensive care unit (NICU) with at least one of the clinical features suggestive of sepsis 5 were included in the study.

The exclusion criteria were neonates who have already been started on antibiotics before admission to NICU. Babies with jaundice were included had all other regular causes ruled out. 


\section{Data collection}

Demographic data, clinical symptoms and examination findings were recorded for all the neonates who were fitting into the inclusion criteria. This included sex, gestational age, age of onset of symptoms, clinical features suggestive of sepsis, vital signs and systemic findings.

\section{Laboratory Diagnosis}

All newborns included underwent a septic screening6,7 as per the NICU protocol. Blood was collected from peripheral vein under all aseptic precautions prior to starting antibiotic treatment. $1 \mathrm{ml}$ of blood was collected for blood cultures and transferred to BACTEC bottles. Blood sample of $2 \mathrm{ml}$ each was then collected in plain vacutainer as well as in EDTA vacutainer. Plain vacutainer for CRP estimation and EDTA vacutainer for total leucocyte count, platelet count, preparation of peripheral smears and for measurement of micro ESR.

\section{Interpretation of results}

Findings which were consistent with sepsis were considered if at least 2 out of 5 criteria were fulfilled in the haematological scoring system. Cultures were considered positive if it has a significant yield of an organism known to cause bacteremia. Organisms usually known to contaminate skin were also included if the yield was significant as the neonates included were symptomatic. Neonates were then analysed in three groups depending on their results - Limb 1: Proven sepsis, Limb 2: Probable sepsis and Limb 3: Clinical sepsis.

\section{Calculation of IT2}

Calculation of $\mathrm{I} / \mathrm{T}$ ratio was done by dividing the total immature neutrophil count by total neutrophil count. IT2 was taken by dividing the total neutrophil count again with this value. Normal IT ratio was considered to be $<0.2$.

IT2 $=\underline{\text { Total immature neutrophil count }}$

Total neutrophil count

\section{$\underline{\text { Statistical analysis }}$}

Statistical analysis was done using Statistical Package of Social Sciences (SPSS) version 17.0. Demographic data were analysed by mean and standard deviation. Pearsons chi square tests were done to analyse categorical data. Continuous variables were analysed by ANOVA. P value $<0.05$ will be considered as significant. The diagnostic accuracy of IT2 ratio with septic screen positivity and blood cultures were assessed by creating a receiver operator curve (ROC) and the area under the curve (AUC) was calculated.

\section{Results}

Of the 304 newborns eligible for the study, 254 were included. 8 newborns were discharged against medical advice, 29 newborns were already started on antibiotics before including in the study, 7 newborns had laboratory error in reporting and 6 newborns had congenital anomalies.
The neonates were then divided into three groups depending on blood culture and septic screen as follows: culture positive sepsis, probable sepsis and clinical sepsis. Baseline characteristics like sex, gestational age, birth weight, number of days the newborn received antibiotics and number of days of NICU stay were compared in each group as depicted in Table 1. All were subjected to septic screening, along with which I/T2 ratio was calculated, the means of which were highly significant when compared between the three groups as shown in [Table 1].

\begin{tabular}{|}
\hline Table 1: Clinical features suggestive of neonatal sepsis5 \\
\hline Sl. No. & Clinical Features \\
\hline 1 & $\begin{array}{l}\text { Neurological: convulsions, drowsy or unconscious, } \\
\text { decreased activity, bulging fontanelle }\end{array}$ \\
\hline 2 & $\begin{array}{l}\text { Respiratory: Respiratory rate >60/min, grunting, severe chest } \\
\text { indrawing, central cyanosis }\end{array}$ \\
\hline 3 & Cardiac: poor perfusion, rapid and weak pulse \\
\hline 4 & $\begin{array}{l}\text { Gastrointestinal: Jaundice, poor feeding, abdominal } \\
\text { distension }\end{array}$ \\
\hline 5 & $\begin{array}{l}\text { Dermatological: skin pustules, periumbilical erythema or } \\
\text { purulence }\end{array}$ \\
\hline 6 & $\begin{array}{l}\text { Musculoskeletal: edema or erythema overlying bones or } \\
\text { joints }\end{array}$ \\
\hline 7 & Temperature >37.7 C or <35.5 C \\
\hline
\end{tabular}

Table 2:

\begin{tabular}{|l|l|l|}
\hline $\begin{array}{l}\text { Sl. } \\
\text { No. }\end{array}$ & Laboratory Parameter & Positive For Sepsis \\
\hline 1. & Total leucocyte count & $<5000 / \mathrm{mm} 3,>30,000 / \mathrm{mm} 3$ \\
\hline 2. & Immature/total neutrophils & $>0.2$ \\
\hline 3. & Micro-ESR & $>15 \mathrm{~mm}$ in first hour \\
\hline 4. & C reactive protein (CRP) & $>6 \mathrm{mg} / \mathrm{dl}$ \\
\hline 5. & Absolute neutrophil count & $\begin{array}{l}\text { As per Manroe and Mouzinho's } \\
\text { chart8 }\end{array}$ \\
\hline 6. & Platelet count & $<1.5 * 105$ cells $/ \mathrm{mm} 3$ \\
\hline
\end{tabular}

Table 3: Baseline Characteristics - mean and standard deviation

\begin{tabular}{|l|l|l|l|l|}
\hline Variable & $\begin{array}{l}\text { Proven } \\
\text { sepsis }\end{array}$ & $\begin{array}{l}\text { Probable } \\
\text { sepsis }\end{array}$ & $\begin{array}{l}\text { No } \\
\text { sepsis }\end{array}$ & p value \\
\hline $\begin{array}{l}\text { Sex (n,\%) } \\
\text { • Male } \\
\text { - Female }\end{array}$ & $31(47)$ & $26(36.1)$ & $50(43.5)$ & 0.410 \\
\hline $\begin{array}{l}\text { Gestational age } \\
\text { (weeks) }\end{array}$ & $34.6 \pm 2.6$ & $46(63.9)$ & $65(56.5)$ & \\
\hline $\begin{array}{l}\text { Birth weight } \\
\text { (kg) }\end{array}$ & $2 \pm 0.83$ & $1.9 \pm 0.68$ & $2.3 \pm 0.65$ & 0.002 \\
\hline $\begin{array}{l}\text { Number of days } \\
\text { of antibiotics }\end{array}$ & $16.1 \pm 8.3$ & $11 \pm 5.8$ & $4.8 \pm 2$ & $<0.001$ \\
\hline Days in NICU & $20 \pm 12.4$ & $14.6 \pm 9.9$ & $5 \pm 3.4$ & $<0.001$ \\
\hline
\end{tabular}

ROC curve was created to assess the value of I/T2 ratio in diagnosing true blood culture positive sepsis in comparison with ANC and I/T ratio individually. ROC curve is depicted in [Figure 1]. AUC was then calculated for all the three and found to be $0.822,0.809$ and 0.610 for $\mathrm{I} / \mathrm{T} 2$ ratio, $\mathrm{I} / \mathrm{T}$ ratio and ANC respectively; the $\mathrm{p}$ value of which is 0.001 . While plotting the ROC curve, we tried to find an ideal cut off point for the I/T2 ratio which was 0.01 . Subsequently, we also tried to find out according to our data, the sensitivity 
and specificity of the known cut off of I/T ratio of 0.2 . Surprisingly, we found the highest specificity and sensitivity for a cut off of 0.12 , suggesting that the newborns with proven, culture positive sepsis had a value of I/T ratio much lower than the established cut off. The sensitivity, specificity, positive predictive value and negative predictive value of IT2 was $62.1 \%, 91.4 \%, 71.9 \%$ and $87.2 \%$ respectively. Similarly, the sensitivity, specificity, positive predictive value and negative predictive value of IT was $65.2 \%, 87.8 \%, 65.2 \%$ and $87.8 \%$ respectively. Also, the sensitivity, specificity, positive predictive value and negative predictive value of Absolute neutrophil count(ANC) was 45.4\%, 76.6\%, 40.5\% and $80 \%$ respectively. This shows that I/T2 has a considerably higher specificity and negative predictive value when compared to I/T ratio, while the sensitivity and specificity of ANC in detecting a proven sepsis is much lower than $\mathrm{I} / \mathrm{T}$ or $\mathrm{I} / \mathrm{T} 2$ ratios. A detailed subgroup analysis of I/T2 ratio $(<0.01)$ in different ranges of ANC $(<500,500-999,1000-1499$ and $>1500$ ), a $p$ value of 0.06 was attained which did not show any significant difference.

Table 4: Mean and standard deviation of septic screen and other haematological parameters

\begin{tabular}{|c|c|c|c|c|}
\hline $\begin{array}{l}\text { Blood } \\
\text { investigation }\end{array}$ & $\begin{array}{l}\text { Proven } \\
\text { sepsis }\end{array}$ & $\begin{array}{l}\text { Probable } \\
\text { Sepsis }\end{array}$ & $\begin{array}{l}\text { No } \\
\text { sepsis }\end{array}$ & p value \\
\hline $\begin{array}{l}\text { Hemoglobin } \\
(\mathrm{g} / \mathrm{dl})\end{array}$ & $14.7 \pm 3.2$ & $16.7 \pm 3.4$ & $17.1 \pm 2.3$ & $<0.001$ \\
\hline $\begin{array}{l}\text { WBC } \\
\text { (cells/mm3) }\end{array}$ & $9.8 \pm 5.1$ & $12.8 \pm 6.3$ & $16.6 \pm 7$ & $<0.001$ \\
\hline $\begin{array}{l}\text { Platelets ( * } 105 \\
\text { cells/mm3) }\end{array}$ & $1.7 \pm 0.95$ & $2.3 \pm 1$ & $2.5 \pm 0.83$ & $<0.001$ \\
\hline $\begin{array}{l}\text { ANC } \\
\text { (cells/mm3) }\end{array}$ & $\begin{array}{l}578.6 \pm \\
400 \\
\end{array}$ & $759.9 \pm 457$ & $\begin{array}{l}945.2 \pm \\
590\end{array}$ & $<0.001$ \\
\hline $\mathrm{I} / \mathrm{T}$ ratio & $0.24 \pm 0.14$ & $0.13 \pm 0.13$ & $\begin{array}{l}0.04 \pm \\
0.03\end{array}$ & $<0.001$ \\
\hline $\mathrm{I} / \mathrm{T} 2$ ratio & $\begin{array}{l}0.033 \pm \\
0.03\end{array}$ & $\begin{array}{l}0.012 \pm \\
0.012\end{array}$ & $\begin{array}{l}0.003 \pm \\
0.004\end{array}$ & $<0.001$ \\
\hline CRP (mg/dl) & $27.9 \pm 25.2$ & $17.2 \pm 22.7$ & $9.2 \pm 13.5$ & $<0.001$ \\
\hline $\begin{array}{l}\text { Micro ESR (mm } \\
\text { of } \mathrm{H} 2 \mathrm{O})\end{array}$ & $10.3 \pm 4.5$ & $9.3 \pm 4.4$ & $7.6 \pm 3.9$ & $<0.001$ \\
\hline
\end{tabular}

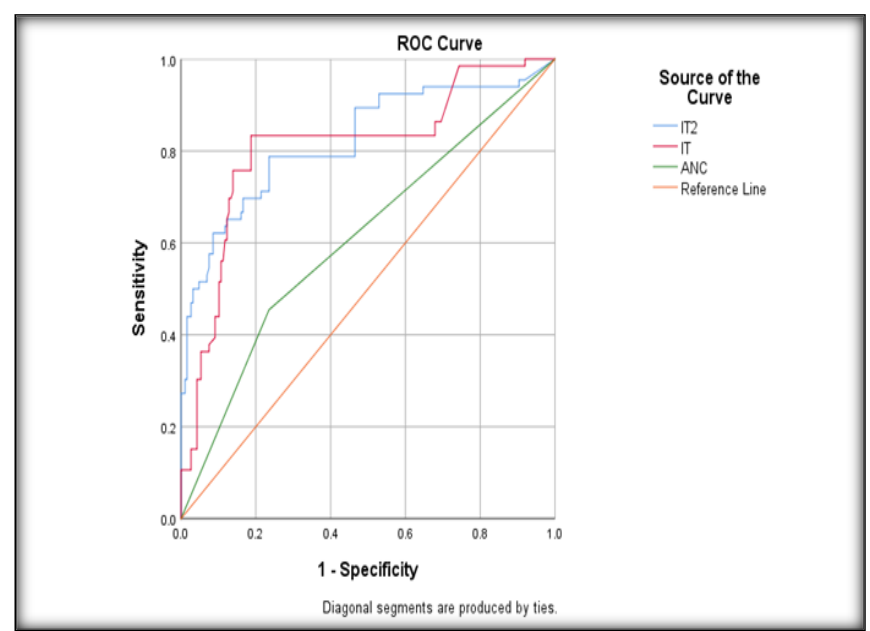

Graph 1. ROC Curve comparing IT, IT2 and ANC (< 500/mm3)
Table 5: Comparison of sensitivity, specificity, positive predictive value and negative predictive value of $I / T$ ratio, IT2 ratio and $A N C$.

\begin{tabular}{|l|l|l|l|l|}
\hline Parameter & Sensitivity & Specificity & PPV & NPV \\
\hline I/T & $65.2 \%$ & $87.8 \%$ & $65.18 \%$ & $87.8 \%$ \\
\hline I/T2 & $62.1 \%$ & $91.4 \%$ & $71.9 \%$ & $87.2 \%$ \\
\hline $\begin{array}{l}\text { ANC }(< \\
500 / \mathrm{mm} 3)\end{array}$ & $45.4 \%$ & $76.6 \%$ & $40.5 \%$ & $80 \%$ \\
\hline $\begin{array}{l}\text { ANC }(< \\
1500 / \mathrm{mm} 3)\end{array}$ & $95.3 \%$ & $10.7 \%$ & $27.1 \%$ & $86.9 \%$ \\
\hline \begin{tabular}{l} 
p value $-<0.001$ \\
\hline
\end{tabular} & & & \\
\hline
\end{tabular}

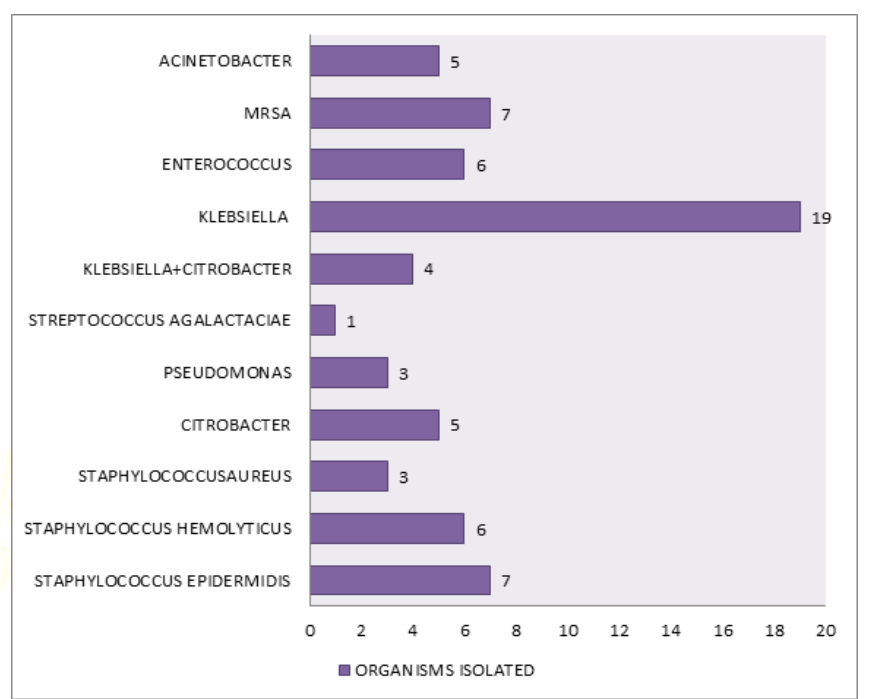

Figure 1: Organisms isolated in blood culture

\section{Discussion}

Sepsis is a systemic inflammatory response to infection and so isolating the causative organism is a must. Although blood culture is the gold standard, it might be important to remember that a larger amount of blood might yield a better culture which may not be possible in neonates. Also, the time taken for a blood culture to grow an organism might vary from $24-48$ hours.8This makes it imperative to device an effective screening tool for neonatal sepsis which is close to blood culture in terms of accuracy.

I/T2 ratio has shown to have better specificity and almost similar sensitivity to ANC and I/T ratio individually and hence is ideal to be used as an independent marker for screening neonatal sepsis. ${ }^{[8]}$ The importance of I/T2 ratio lies in the fact that in the case of low total neutrophil count, a high I/T ratio may be seen which might screen falsely negative for sepsis. This can be avoided by calculation of I/T2, especially where the sepsis was detected in newborns due to low total count. ${ }^{[8]}$

There is a lot of discrepancy in the cut-off values taken for $\mathrm{I} / \mathrm{T}$ ratio in different studies evaluating different parameters of neonatal sepsis. While many standard references mention an I/T ratio of more than 0.3 to be indicative of sepsis, ${ }^{[9]}$ most of the studies done on neonatal sepsis considers a cutoff of more than 0.2 for its diagnosis. Schmutz et al showed 
that a single value of $\mathrm{I} / \mathrm{T}$ ratio of $>0.3 \mathrm{had}$ a high NPV(99\%)but a very poor PPV(25\%). ${ }^{[7,10-13]}$ Recently, increasing $\mathrm{I} / \mathrm{T}$ ratios were shown to have increasing logistic regression values, highest for a cut-off $>0.60$ at $\geq 4$ hours (10.7) in 245 neonates with culture-proven sepsis. ${ }^{[14]}$ However in our study, we initially considered any value $>0.2$ in our inclusion criteria, but we found out highest specificity and sensitivity for a cut off of 0.12 , suggesting that the newborns with proven, culture positive sepsis had a value of I/T ratio much lower than the established cut offs of either 0.2 or 0.3 . This is consistent with a study done by Diana et $a{ }^{[15]}$ where the reference value of $\mathrm{I} / \mathrm{T}$ ratio in healthy newborns were 0.01-0.13 (mean 0.06), in sepsis neonates $0.13-0.60$ (median 0.26 ) and the cut off value for sepsis detection was 0.13 and they concluded that I/T ratio could be used as a marker for early detection of newborn septicaemia.

In a prospective study of 150 neonates 32-38 weeks gestational age with early onset sepsis, the sensitivity of an ANC $<8000 / \mathrm{mm} 3$ was $76 \%$ and the negative predictive value was $94 \% .{ }^{[16]}$ In the study done by Newman et al, an ANC $<1000 / \mathrm{mm} 3$ had a $+\mathrm{LR}$ of $7.5,33.5$ and 115 when drawn at $<1,1-3$ and $\geq 4$ hours, respectively, in patients $\geq 34$ weeks with positive culture results. ${ }^{[14]}$ In the study done by Shalini et al, positive septic screen was considered when there was presence of two of the four parameters namely, TLC $(<5000 / \mathrm{mm} 3)$, band to total polymorphonuclear cells ratio of $>0.2$, absolute neutrophil count $<1800 / \mathrm{mm} 3, \mathrm{C}$ reactive protein $(\mathrm{CRP})>1 \mathrm{mg} / \mathrm{dl}$ and micro ESR $>10 \mathrm{~mm}-$ first hour.1In our study, we tried to compare the sensitivity and specificity in predicting sepsis with ANC cut offs of 500 cells/mm3 with 1500 cell/mm3 and found a higher specificity and PPV when the value of 500 cells/mm3 was considered as the cut-off while sensitivity and negative predictive value increased to $95.4 \%$ was $86.9 \%$ with 1500 cells/mm3 at the cut-off, but it lacked good specificity and positive predictive value.

In our study we found that the culture positivity rate was $25.9 \%$ and Klebsiella was the most common organism isolated followed by Staphylococcus epidermidis/ Methicillin Resistant Staphylococcus aureus (MRSA) as opposed to other studies. In a review of blood culture results of neonatal sepsis in the first 90 days of life from 63 centres, the South Asian region appeared to have 9.8\% S. aureus, $0.8 \%$ Group B Streptococcus, 23\% Klebsiella, and 12\% E. coli during the first 28 days of life. ${ }^{[17,18]}$ In a study done by Hamer et al in 2015, S.aureus was the predominant organism in neonatal sepsis, followed by Acinetobacter species, Enterobacter species, E.coli, and Klebsiella. ${ }^{[19]}$

Limitations of the study include a smaller sample size and this was a single centre study. Use of other standard investigations like procalcitonin and CRP wasn't taken into account. I/T2was calculated based on the electronic generated machine value from coulter technique and not by the peripheral smear identification under microscope.

\section{Conclusion}

I/T2 shows promise as a novel, effective, simple method to screen sepsis when used in conjunction with established parameters like ANC and I/T ratio. Its advantage lies in the fact that it does not require special laboratory facilities which makes it useful in the early detection of neonatal sepsis. Additional studies may be required to validate this index in larger populations.

\section{References}

1. ShaliniTripathi,G. K. Malik; Neonatal Sepsis: past, present and future; a review article, Internet Journal of Medical Update 2010 July;5(2):45-54

2. Thaver D, Zaidi AK. Burden of neonatal infections in developing countries:A review of evidence from communitybasedstudies.Pediatr Infect Dis J 2009;28:S3-9.

3. Mathur NB. Neonatal sepsis. Indian Pediatr 1996;33:663-74.

4. Saleh MT, Sherif LS, Elwakkad AS, Assal WAM (2008). Leptin: does it have a role in neonatal sepsis? Journal of Applied Science Research 4, 353-359

5. Robert M, Kliegmann S, Bonita F, Joseph W (ed). Nelson textbook of Pediatrics: First south Asia Edition. Elsevier India; 2015; Vol 1 (109):915

6. Singh.M, Care of the newborn, 8th edition, New Delhi, CBS publishers, 2015. p 290

7. Schmutz N, Henry E, Jopling J, Christensen RD. Expected ranges for blood neutrophil concentrations of neonates: the Manroe and Mouzinho charts revisited. Journal of Perinatology. 2008 Apr;28(4):275.

8. Shah BA, Padbury JF. Neonatal sepsis: an old problem with new insights. Virulence. 2014 Jan 1;5(1):170-8

9. Eichenwald EC, Hansen AR, Martin CR, Stark AR(ed). Cloherty and Stark's manual of neonatal care. Wolters Kluwer (India); 2017; 48:691-693

10. Walliullah SM1, Islam MN, Siddika M, Hossain MA, Chowdhury AK. Role of micro-ESR and I/T ratio in the early diagnosis of neonatal sepsis. Mymensingh Med J. 2009 Jan;18(1):56-61.

11. Ghosh S, Mittal M, Jaganathan G. Early diagnosis of neonatal sepsis using a hematological scoring system. Indian $\mathrm{J}$ Med Sci. 2001;55:495-500

12. Narasimha, A. \&Harendra Kumar, M.L. Indian J Hematol Blood Transfus (2011) 27: 14

13. European Medicines Agency (EMA). Report on the Expert Meeting on Neonatal and Pediatric Sepsis, EMA/477725/2010.

14. Newman TB, Draper D, Puopolo KM, Wi S, Escobar GJ. Combining immature and total neutrophil counts to predict early onset sepsis in term and late preterm newborns: use of the I/T2. The Pediatric infectious disease journal. 2014 Aug;33(8):798.

15. Diana Aulia, Arief I. Sanjaya, and Ina S. Timan. The Use of Immature to Total Neutrophil (IT) Ratio to Detect Bacteriemia in Neonatal Sepsis. J. Lab. Med. \& Quality Assuarance 2003 : 25 : 237-242 237

16. Manucha V, Rusia U, Sikka M, et al. Utility of haematological parameters and C-reactive protein in the detection of neonatal sepsis. J Paediatr Child Health. 2002;38:459-464.

17. Zaidi AK, Thaver D, Ali SA, Khan TA. Pathogens Associated with Sepsis in Newborns and Young Infants in Developing Countries. Pediatr Infect Dis J. 2009; 28:S10-S18. [PubMed: 19106757]

18. Hamer DH, Darmstadt GL, Carlin JB, Zaidi AK, Yeboah-Antwi K, Saha SK, et al. Etiology of Bacteremia in Young Infants in Six Countries. Pediatr Infect Dis J. 2015; 34(1):e1-e8. [PubMed: 25389919]

19. Jackson GL, Engle WD, Sendelbach DM, et al. Are complete blood 


\section{Sanjee et al; Diagnastic Value of J/T2 Ratia in Neanatal Sepsis}

cell counts useful in the evaluation of asymptomatic neonates exposed to suspected chorioamnionitis? Pediatrics 2004; 113: 1173-80.

20. Zaidi AK, Thaver D, Ali SA, Khan TA. Pathogens Associated with Sepsis in Newborns and Young Infants in Developing Countries. PediatrInfect Dis J. 2009; 28:S10-S18.
21. Hamer DH, Darmstadt GL, Carlin JB, Zaidi AK, Yeboah-Antwi K, Saha SK, et al. Etiology of Bacteremia in Young Infants in Six Countries. Pediatr Infect Dis J. 2015; 34(1):e1-e8.

Copyright: () the author(s), 2019. It is an open-access article distributed under the terms of the Creative Commons Attribution License (CC BY 4.0), which permits authors to retain ownership of the copyright for their content, and allow anyone to download, reuse, reprint, modify, distribute and/or copy the content as long as the original authors and source are cited.

How to cite this article: Sanjee SS, Rajan A, Shriyan AR, Soans ST. Diagnostic Value of I/T2 Ratio in Neonatal Sepsis: A Prospective Comparative Study. Asian J. Clin. Pediatr. Neonatol.2019;7(1):12-16.

DOI: dx.doi.org/10.21276/ajcpn.2019.7.1.4 